\title{
Knowledge, Attitudes, and Practices of Cancer Patients Towards COVID-19: A Cross-Sectional Study in Central Nepal
}

This article was published in the following Dove Press journal: Cancer Management and Research

\author{
Guru Sharan Sah ${ }^{1, *}$ \\ Gambhir Shrestha (iD ${ }^{2 *}$ \\ Aayush Dhakal ${ }^{3}$ \\ Rashmi Mulmi ${ }^{4}$ \\ Ashok Sapkota (D) \\ Shivaji Poudel ${ }^{5}$ \\ 'Department of Medical Oncology, B.P. \\ Koirala Memorial Cancer Hospital, \\ Bharatpur, Chitwan, Nepal; ${ }^{2}$ Department \\ of Community Medicine, Maharajgunj \\ Medical Campus, Institute of Medicine, \\ Tribhuvan University, Maharajgunj, \\ Kathmandu, Nepal; ${ }^{3}$ Bharatpur Central \\ Hospital, Bharatpur, Chitwan, Nepal; \\ ${ }^{4}$ Department of Cancer Prevention, \\ Control and Research, B.P. Koirala \\ Memorial Cancer Hospital, Bharatpur, \\ Chitwan, Nepal; ${ }^{5}$ Department of \\ Radiation Oncology, B.P. Koirala \\ Memorial Cancer Hospital, Bharatpur, \\ Chitwan, Nepal \\ *These authors contributed equally to \\ this work
}

Introduction: Cancer patients are at higher risk of COVID-19 infection as they are highly immunocompromised. The patients' adherence to control measures is affected by their knowledge, attitudes, and practices (KAP) towards COVID-19. This study assesses the KAP towards COVID-19 among the admitted cancer patients in Nepal and is first of its kind. Patients and Methods: A cross-sectional study was conducted among the 224 admitted cancer patients in B.P. Koirala Memorial Cancer Hospital, Chitwan, Nepal, between April 20 and May 20, 2020, which was the early phase of the lockdown due to COVID-19. The study was conducted via face-to-face interviews taking optimum precautions. The research used a semi-structured questionnaire consisting of demographic characteristics, cancer-related information, 14 knowledge items, 4 attitude items, and 10 practice items. Independent sample $t$-tests and one-way analysis of variance were used to assess the association of knowledge with demographic characteristics.

Results: The overall correct response rate of the knowledge component of the questionnaire was $79.4 \%$. Most of the participants $(89.7 \%$ ) had a positive attitude towards accepting isolation if they had the COVID-19 infection. Only 4.5\% reported that they had visited the crowded places recently. More than $98 \%$ of the patients were found to be compliant with the recommended preventive behaviors such as using the face mask, avoiding touching the eyes, nose, and mouth, washing the hands more than usual, and avoiding close contact with other patients or the caretakers not using the face masks. A total of $21.9 \%$ of respondents were using the same face mask for more than 3 days. Male gender, younger age group, and higher education were the positive predictors of knowledge regarding COVID-19.

Conclusion: The overwhelming majority of the cancer patients had a good knowledge of COVID-19 and maintained positive attitudes and practice towards it. When tailored health education programs are planned, age, gender, and educational status should be taken into a consideration.

Keywords: COVID-19, neoplasms, knowledge, attitudes and practice, Nepal

\section{Introduction}

Coronavirus Disease -2019 (COVID-19) is an acute febrile respiratory illness caused by a novel coronavirus or Severe Acute Respiratory Syndrome Coronavirus 2 (SARS-CoV-2). It was first reported to the World Health Organization (WHO) on December 31, 2019, as pneumonia of unknown etiology with outbreak clustering in Wuhan city, Hubei province China. ${ }^{1}$ With the rapid rise of cases, the WHO declared it a public health emergency of international concern on January 30, 2020. By June 13, 2020, there were a total of 7,553,182 confirmed
Correspondence: Gambhir Shrestha Department of Community Medicine, Maharajgunj Medical Campus, Institute of Medicine, Tribhuvan University, Maharajgunj, Kathmandu, Nepal Tel +9779841654909

Email gamvir.stha@gmail.com 
cases, with 423,349 deaths. ${ }^{2}$ The first case of COVID-19 in Nepal was confirmed in Kathmandu on January 23, 2020, when a Nepali returnee from Wuhan, China tested positive for COVID-19. In Nepal, there are a total of 5760 confirmed cases of COVID-19 with 19 deaths to date (June 13, 2020). ${ }^{3}$

A wide range of clinical features of COVID-19 from asymptomatic to mild symptoms to serious illness have been reported with an incubation period of 2-14 days. Common symptoms include fever, cough, shortness of breath, fatigue, headache, new-onset loss of taste or smell, sore throat, runny nose, and gastrointestinal symptoms like nausea, vomiting, and diarrhea. ${ }^{4}$ Person-toperson spread via respiratory droplets, or direct contact is the primary mode of transmission of COVID-19. Transmission via asymptomatic carriers has also been well documented. ${ }^{5}$ COVID-19 is highly transmissible, and to date, there is no vaccine or treatment approved for it. In addition to isolation and subsequent management of diagnosed cases, the recommended preventive behaviors to stop the spread of the virus include proper hand hygiene, maintaining the physical distance of at least one meter, avoiding crowded places, avoiding contact with eyes, nose and mouth, maintaining respiratory hygiene and self-isolation even with milder symptoms. ${ }^{6}$ In regards to face mask use, the Centers for Disease Control and Prevention (CDC) recommends the use of cloth face covering for all individuals in public settings even if the person is asymptomatic, or has a fever or mild symptoms of COVID-19. It is further recommended to wash cloth face-covering after each use and allow it to dry completely before reuse. $^{7}$

Several independent clinical risk factors like old age (more than 65 years), smoking history, presence of comorbid conditions, including hypertension, diabetes, cardiovascular disease, respiratory disease, and cancer increase the risk of developing critical illness and mortality in COVID-19 patients. ${ }^{8,9}$

Cancer patients are highly immunocompromised due to the disease itself, comorbidities, and anti-cancer treatment, and hence they are at risk of COVID-19 infection. A study done in Italy reported that $20 \%$ of 355 patients who died of COVID-19, had active cancer. ${ }^{10}$ A cohort study on the clinical impact of COVID-19 on patients with cancer showed higher 30-day-all-cause mortality among cancer patients. ${ }^{11}$ The Report of the WHO-China Joint Mission on Coronavirus disease 2019 indicated that the case fatality rates among patients with cancer and COVID-19 diagnosed before February 20, 2020, was 7.6\%, which was higher than the overall case fatality rate $(3.8 \%){ }^{12}$

According to the GLOBOCAN report on Nepal 2018, there were 28,184 new cancer cases, and 19,413 deaths during the year 2018 with an age-standardized incidence rate of $103.7 / 100,000$, while the mortality rate was 77.8 / 100,000. Excluding non-melanoma skin cancer, the top five most frequent cancer were carcinoma lung, cervix, breast, gallbladder, and stomach. ${ }^{13}$ The majority of Nepal's cancer cases are treated in the B.P. Koirala Memorial Cancer Hospital (BPKMCH), the national comprehensive cancer center with 450 beds. The BPKMCH annual report 2018 mentions that out of a total of 5334 patients of various cancer recorded in one year, the maximum number of cancer diagnoses was present in the age group of 60-64 years (684/5334). Among these new cases, $62.26 \%$ of cases were diagnosed in patients above 50 years $(3,321 / 5334) .{ }^{14}$ Therefore, at the BPKMCH, most patients with cancer are older with comorbid conditions, both of which are established risk factors for developing critical illness with COVID-19 infection. The ongoing outpatient and inpatient services at the BPKMCH could be severely affected by the outbreak of COVID-19 in the hospital's vicinity and can result in a serious outcome. This further increases the risk to the cancer patients and the hospital staff and creates challenges to provide the patient healthcare services. It is very important for cancer patients to adhere to the recommended preventive measures. Adherence to these preventive measures is directly affected by their knowledge, attitude, and practice (KAP) towards COVID-19. An awareness on the preventive measures of COVID-19 is critical to reducing the infection. With this realization of urgency, we conducted the present study to access KAP regarding the COVID-19 among the cancer patients in the BPKMCH. The results of this study will help health authorities plan appropriate strategies to educate and raise awareness on preventive measures of COVID-19 among the cancer patients in the hospital.

\section{Patients and Methods}

\section{Study Design and Sampling Technique}

This study used a cross-sectional design and was conducted at the BPKMCH, Bharatpur, Chitwan, Nepal. It was done during the lockdown period in Nepal between April 20 to May 20, 2020. The study included the participants who were admitted to the hospital for the treatment of cancer and were above 18 years of age. The patients 
from outpatient and emergency departments were not included in this study. The participants were selected via purposive sampling where we interviewed all available at our convenient time.

\section{Study Instrument}

A semi-structured questionnaire was used which included, demographic variables, cancer-related variables, and KAP. KAP questionnaire was constructed by adapting the measures developed in a previous study among the Chinese residents' KAP towards COVID-19. ${ }^{15}$ To measure knowledge on COVID-19, 14 items were included with a response of "yes", "no' or "I don't know". A correct response to an item was scored 1, while an "incorrect/ don't know" response was scored 0 points. To measure attitudes towards the disease, the participants were surveyed whether they agreed or disagreed to their probability of getting infected with COVID-19, whether they were worried that one of their family members and treating health workers would get infected, and whether they would accept or reject isolation if they got ill. To measure practices, the participants were asked whether they visited crowded places recently, wore facemasks, avoided touching face, eyes, and mouth without washing hands, avoided meeting with relatives, avoided going near the other patients and patients' visitors, and caretakers. They were also asked about the number of caretakers, the place where they were staying, and whether their caretakers were taking proper preventive measures against COVID-19, such as regular hand washing, wearing masks, and so on. Other questions on practices included information on the types of facemask used, frequency of changing facemask, and frequency of handwashing practice. The questionnaire was validated by two independent experts. The KAP questionnaire was piloted among 15 visitors in the $\mathrm{BPKMCH}$ and necessary amendments were done. It was conducted via face-to-face interviews administered by the research team (not involved in patient care), taking optimum precautions.

\section{Ethical Approval}

Ethical approval for this study was obtained from the Institutional Review Committee, BPKMCH (Ref. no. 1987/2076/77), and this study was conducted in accordance with the Declaration of Helsinki. An informed verbal consent (approved by the Institutional Review Committee) was taken from the participants before data collection. All standard precautions were adopted during interaction with patients by the research team (not involved in patient care), and it was ensured that the patients and their caregivers got necessary information on COVID-19 at the end of data collection.

\section{Statistical Analysis}

The data were entered in Microsoft Excel 2013 and analyzed in the Statistical Package for Social Sciences version 20. Descriptive analysis was applied to show the demographic characteristics, the cancer-related information, and the KAP among cancer patients. Independent sample $t$-tests and oneway analysis of variance (ANOVA) were applied to compare mean scores of the knowledge with selected demographic variables. A p-value of 0.05 was taken as the cutoff point for statistical significance. The Cronbach's alpha coefficient was used to measure the internal consistency of the knowledge questionnaire, which was 0.85 in our sample, indicating excellent reliability.

\section{Results}

\section{Demographic and Cancer-Related Characteristics}

A total of 224 cancer patients were included in this study with the mean age of 49.5 years (SD 16.4). Out of the total participants, 54\% were females, the majority were married, and $73 \%$ were Hindu by religion. Almost half (45.5\%) were illiterate. The average hospital stay was 5.7 days (SD 3.6), ranging from 0 to 30 days. The most common cancer among the participants was gastrointestinal $(21 \%)$, followed by gynecological (18\%) and genitourinary $(14 \%)$. More than half of them were receiving chemotherapy, followed by radiotherapy, while $16 \%$ were follow-up surgery patients (Table 1).

\section{Knowledge Assessment}

The overall correct response rate of the knowledge component of the questionnaire was found to be $79.4 \%$. Regarding each knowledge question, $31.7 \%$ of participants did not know about the agent of COVID-19. The majority knew the source of transmission, clinical features, and its preventive measures. The majority were aware that chronic illnesses like cancer pose a higher risk of morbidity and mortality from COVID-19. They were also aware that their caregivers should take enough preventive measures so that the virus is not transmitted to them (Table 2).

The average knowledge score was found to be 11.1 (SD 3.0) ranging from a minimum score of 2 to a maximum score of 14. The knowledge score of old cancer patients 
Table I Demographic and Cancer Related Information of Cancer Patients $(\mathrm{N}=224)$

\begin{tabular}{|l|l|l|}
\hline Variables & Categories & $\mathbf{n}(\%)$ \\
\hline Age in years & $18-40$ & $73(32.6)$ \\
& $40-60$ & $82(36.6)$ \\
& $>60$ & $69(30.8)$ \\
\hline Gender & Male & $103(46.0)$ \\
& Female & $121(54.0)$ \\
\hline Marital status & Married & $216(96.4)$ \\
& Unmarried & $8(3.6)$ \\
\hline \multirow{2}{*}{ Religion } & Hindu & $164(73.2)$ \\
& Buddhist & $43(19.2)$ \\
& Muslim & $13(5.8)$ \\
& Christian & $4(1.8)$ \\
\hline \multirow{2}{*}{ Education } & Illiterate & $102(45.5)$ \\
& Primary level (up to 5) & $16(7.2)$ \\
& 6-I0 class & $96(42.9)$ \\
& More than I0 & $10(4.4)$ \\
\hline \multirow{5}{*}{ Type of cancer } & Gastrointestinal & $48(21.4)$ \\
& Gynecological & $41(18.3)$ \\
& Genitourinary & $32(14.3)$ \\
& Lung & $25(11.2)$ \\
& Colorectal & $21(9.4)$ \\
& Breast & $18(8.0)$ \\
& Head and neck & $15(6.7)$ \\
& Hematological & $12(5.4)$ \\
& Soft tissue & $11(4.9)$ \\
& Neurological & $128(0.4)$ \\
\hline & Chemotherapy & $50(22.3)$ \\
& Radiotherapy & \\
& & $(15.6)$ \\
\hline
\end{tabular}

(>60 years) was comparatively lower than that of 40-60 years and 18-40 years (mean 9.5 VS 11.5 VS 12.3). This difference was found to be statistically significant $(\mathrm{p}<0.001)$. Similarly, male participants had a higher knowledge score than their counterparts (mean 11.7 VS 10.6) and this difference was found to be significant ( $\mathrm{p}=0.008$ ). Higher education was found to be the positive predictor of knowledge regarding COVID-19 $(\mathrm{p}<0.001)$ (Table 3).

\section{Attitudes Assessment}

The majority $(81 \%)$ reported that they would probably be infected by COVID-19. Likewise, $71 \%$ and $69 \%$ reported that they were worried that their caregivers and health professionals might get infected. Almost $90 \%$ of the participants had a positive attitude towards isolation and reported that they would accept it if they got infected with COVID-19 (Table 4).

\section{Practices Assessment}

Almost all participants were practicing preventive measures against COVID-19. Except for a few participants $(4.5 \%)$, all other patients mentioned that they had not visited the crowded places recently. More than $98 \%$ of patients were found to be compliant with the recommended preventive behaviors like using a face mask, avoiding touching eyes, nose and mouth, avoiding close contact with other patients or caretakers not using a face mask, and washing hands more than usual. Almost all (99.6\%) patients agreed that their caretakers performed hand hygiene, each time upon return to their rooms from outside (Table 5).

The BPKMCH has issued notice to allow only one caretaker for each patient. To estimate the overcrowding status in the hospital, we assessed the number of caretakers for each patient. The result showed that the total number of patients with one caretaker and that with two caretakers were almost equal (43.3\% vs $42.9 \%$ ). Likewise, $10 \%$ had 3 and more caretakers, while $4 \%$ had none. Regarding the accommodation of caretakers, they reported that $65.5 \%$ stayed in the hospital premises, $31 \%$ in the hotel, and $3.5 \%$ stayed at their home or relative's place. When inquired about the type of masks used, it was observed that $69 \%$ were using cotton masks, $25 \%$ patients were using surgical masks, $2.6 \%$ patients using both surgical and cotton mask, and 3 patients using N-95 respirators. However, 4 patients denied using a face mask of any type and $21.9 \%$ of the respondents were using the same face mask for more than 3 days (Table 6).

\section{Discussion}

To the best of our knowledge, this study is the first of its kind in Nepal. As patients with chronic diseases are at higher risk of morbidity and mortality from COVID-19, these patients should take optimum preventive measures. Nepal's first confirmed case on January 23, 2020, and the second case on March 22, 2020, had a history of international travel. ${ }^{16}$ The Government of Nepal had implemented lockdown across the entire country since March 24, 2020, stopping all non-essential services, travel, and trade. The BPKMCH is educating and promoting the standard precautions of COVID-19 among the patients and carrying out Polymerase Chain Reaction (PCR) testing of 
Table 2 Knowledge Regarding COVID-19 Among the Cancer Patients (N=224)

\begin{tabular}{|c|c|c|c|}
\hline Knowledge * & Yes n(\%) & No $n(\%)$ & $\begin{array}{l}\text { Do not } \\
\text { Know } n(\%)\end{array}$ \\
\hline I. COVID-19 is a virus (microorganism) infection (yes) & $153(68.3)$ & - & $7 \mid(31.7)$ \\
\hline 2. COVID-19 is transmitted by close contact with the infected person (yes) & $218(97.3)$ & I (0.4) & $5(2.2)$ \\
\hline 3. Fever, cough, sore throats and shortness breath are possible symptoms of COVID-I9 (yes) & $212(94.6)$ & I (0.4) & II (4.9) \\
\hline 4. COVID-19 vaccine is available in markets (no) & $13(5.8)$ & $107(47.8)$ & $104(46.4)$ \\
\hline 5. There currently is no effective cure for COVID-2019 (yes) & $108(48.2)$ & $19(8.5)$ & $97(43.3)$ \\
\hline 6. Early symptomatic and supportive treatment can help most patients recover from the infection (yes) & $176(78.6)$ & - & $48(21.4)$ \\
\hline $\begin{array}{l}\text { 7. Washing hands with soap and water, and using face masks can help in the prevention of disease } \\
\text { transmission (yes) }\end{array}$ & $221(98.7)$ & I $(0.4)$ & $2(0.9)$ \\
\hline 8. Patients with underlying chronic diseases are at a higher risk of infection and death (yes) & $201(89.7)$ & - & $23(10.3)$ \\
\hline 9. COVID-19 could be fatal (yes) & $196(87.5)$ & $2(0.9)$ & $26(11.6)$ \\
\hline 10. Healthcare workers are at a higher risk of infection (yes) & $165(73.7)$ & $2(0.9)$ & $57(25.4)$ \\
\hline $\begin{array}{l}\text { II. Not all persons with COVID-19 will develop to severe cases. Only those who are elderly, have } \\
\text { chronic illnesses, and are obese are more likely to be severe cases. (yes) }\end{array}$ & $200(89.3)$ & - & $24(10.7)$ \\
\hline 12. Persons with COVID-19 cannot infect the virus to others when a fever is not present. (no) & $5(2.2)$ & II 8 (52.7) & $101(45.1)$ \\
\hline $\begin{array}{l}\text { 13. It is not necessary for care givers to take measures to prevent the infection by the COVID-I9 virus. } \\
\text { (no) }\end{array}$ & $6(2.7)$ & $192(85.7)$ & $26(11.6)$ \\
\hline $\begin{array}{l}\text { 14. To prevent the infection by COVID-19, individuals should avoid going to crowded places such as } \\
\text { party and avoid taking public transportations. (yes) }\end{array}$ & $223(99.6)$ & I (0.4) & - \\
\hline
\end{tabular}

Note: *Correct answer is in the parenthesis.

Table 3 Association of Knowledge with Demographic Variables of Cancer Patients ( $N=224)$

\begin{tabular}{|c|c|c|c|c|}
\hline Variables & Categories & Knowledge score (Mean \pm SD) & $\mathbf{t} / \mathbf{f}$ & p-value \\
\hline Age in years & $\begin{array}{l}18-40 \\
40-60 \\
>60\end{array}$ & $\begin{array}{l}12.32 \pm 2.15 \\
11.45 \pm 2.73 \\
9.45 \pm 3.48\end{array}$ & 19.234 & $\begin{array}{l}<0.001 \\
<0.001 \\
\text { Ref }\end{array}$ \\
\hline Gender & $\begin{array}{l}\text { Male } \\
\text { Female }\end{array}$ & $\begin{array}{l}11.69 \pm 2.62 \\
10.63 \pm 3.29\end{array}$ & 2.686 & $\begin{array}{l}0.008 \\
\text { Ref }\end{array}$ \\
\hline Education & $\begin{array}{l}0-5 \\
>6\end{array}$ & $\begin{array}{l}10.04 \pm 3.27 \\
|2.3| \pm 2.23\end{array}$ & -6.114 & $\begin{array}{l}<0.001 \\
\text { Ref }\end{array}$ \\
\hline
\end{tabular}

Table 4 Attitudes Regarding COVID-19 Among the Cancer Patients ( $N=224)$

\begin{tabular}{|l|l|l|l|}
\hline Attitudes & Yes n(\%) & No n(\%) & Do not Know n(\%) \\
\hline I. You think you will probably get illness & $181(80.8)$ & $14(6.3)$ & $29(12.9)$ \\
2. You are worried one of your caretakers may get an infection & $159(71.0)$ & $34(15.2)$ & $31(13.8)$ \\
3. You are worried one of your health professionals may get an infection & $155(69.2)$ & $38(17.0)$ & $31(13.8)$ \\
4. If you get COVID-19, you will accept isolation in health facilities & $201(89.7)$ & $6(2.7)$ & $17(7.6)$ \\
\hline
\end{tabular}

patients with suspected infections, patients undergoing surgery, or receiving cytotoxic chemotherapy.

This study found that, despite a higher percentage of illiterate respondents $(45.5 \%)$, the majority of the patients $(68.3 \%)$ were aware that COVID-19 is caused by a microorganism. A significant number of patients (79.4\%) were familiar with the common symptoms of COVID-19, its transmission route, and the preventive measures. The findings suggest that a better knowledge of COVID-19 in the participants can be attributed to the repeated and prolonged health-care contact, the observation of additional preventive measures adopted by health-care providers, and widespread information circulated by the government through various means. 
Table 5 Practice Regarding COVID-19 Among the Cancer Patients ( $N=224)$

\begin{tabular}{|l|l|l|l|}
\hline Practices & Yes n(\%) & No n(\%) & Do not Know n(\%) \\
\hline I. In recent days, have you gone to any crowded place? & $10(4.5)$ & $214(95.5)$ & - \\
2. In recent days, have you been wearing face masks? & $220(98.2)$ & $4(1.8)$ & - \\
3. Have you avoided touching your eyes, mouth and nose without washing hands? & $221(98.7)$ & $2(0.9)$ & $1(0.4)$ \\
4. Have you avoided meeting with relatives in recent days? & $222(99.1)$ & $2(0.9)$ & - \\
5. Do you avoid going near with other patients and patient party who are not using mask? & $223(99.6)$ & $1(0.4)$ & - \\
6. Does your caretaker wash hand after going outside each time? & $223(99.6)$ & - & $1(0.4)$ \\
\hline
\end{tabular}

This study also found that majority of the patients knew the fact that the presence of comorbid conditions increases their risk of infection and death. A large proportion of respondents also showed concern that their family members $(71 \%)$ or health-care providers $(69.2 \%)$ would get infected with COVID-19, which would later transmit to them. Apart from dealing with a cancer diagnosis and frequent hospital visit for treatment and follow-up, the

Table 6 Other Practices in the Hospital Among the Cancer Patients $(\mathrm{N}=224)$

\begin{tabular}{|c|c|c|}
\hline Practices & Categories & $n(\%)$ \\
\hline 7a. Number of caretakers & $\begin{array}{l}0 \\
1 \\
2 \\
3 \\
4\end{array}$ & $\begin{array}{l}9(4.0) \\
97(43.3) \\
96(42.9) \\
20(8.9) \\
2(0.9)\end{array}$ \\
\hline 7b. Stay of caretakers & $\begin{array}{l}\text { Hospital } \\
\text { Hotel } \\
\text { Relative's house } \\
\text { Own house/rent }\end{array}$ & $\begin{array}{l}147 \\
(65.6) \\
69(30.8) \\
1(0.4) \\
7(3.1)\end{array}$ \\
\hline 8. Frequency of hand wash & $\begin{array}{l}\text { More than before } \\
\text { As usual }\end{array}$ & $\begin{array}{l}220 \\
(98.2) \\
4(1.8)\end{array}$ \\
\hline 9. Type of masks used & $\begin{array}{l}\text { Cotton } \\
\text { Surgical mask } \\
\text { Both cotton and } \\
\text { surgical } \\
\text { N-95 } \\
\text { Do not wear }\end{array}$ & $\begin{array}{l}154 \\
(68.8) \\
57(25.5) \\
6(2.6) \\
3(1.3) \\
4(1.8)\end{array}$ \\
\hline $\begin{array}{l}\text { 10. Frequency of change of } \\
\text { mask }\end{array}$ & $\begin{array}{l}\text { One mask per day } \\
\text { In every alternate day } \\
\text { In } 3 \text { days or more } \\
\text { Reuse after washing } \\
\text { Do not wear }\end{array}$ & $\begin{array}{l}5(2.2) \\
9(4.0) \\
49(21.9) \\
157 \\
(70.1) \\
4(1.8)\end{array}$ \\
\hline
\end{tabular}

patients receiving care at the $\mathrm{BPKMCH}$ were found to be significantly optimistic and motivated towards the prevention of COVID-19, despite the increased level of difficulty in transportation and logistics due to lockdown. This was supported by their positive attitude towards the importance of isolation and the expression of willingness to accept isolation if they get infected with COVID-19.

In comparison to the KAP among patients with musculoskeletal and rheumatological disease in Nepal, a higher proportion of cancer patients could identify the common symptoms of COVID-19 (94.6\% VS 91.6\%) and have adopted preventive behaviors like wearing facecovering (98.2\% VS 94.7\%). However, a lower proportion of patients in this study were found to be avoiding crowded places (95.5\% VS 97.9\%). ${ }^{17}$ The reason might be that this research was conducted among the inpatients, while the other study was web-based. The status of patients' hospitalization with their daily interaction with health-care providers and a need to access transportation service and travel could have contributed to the difference in results between these studies. In this study, the male gender, younger age group, and higher education level were associated with higher knowledge of COVID-19. This finding is analogous to a survey among the Malaysian public, ${ }^{18}$ while it stands in contrast with the study among patients with the musculoskeletal and rheumatological disease, which shows no significant relationship with gender and education. ${ }^{17}$

Unlike the previous study among the general population in Nepal, which included a majority of young and educated participants with access to the internet, and 34\% participants related to health care, ${ }^{19}$ this study involved a significant number of patients who were either illiterate $(45.5 \%)$ or with secondary or lower education level $(50.1 \%)$. Despite low levels of formal education and literacy, good knowledge and practice regarding COVID-19 were observed in cancer patients at the BPKMCH. Since $89.7 \%$ agreed that having a comorbid condition increases 
the risk of infection and death, these findings could be attributed to increased concern, seeking out for information to prevent COVID-19, and practicing them consistently with self-realization that they are one of the vulnerable groups to develop severe COVID-19 infection.

A higher number of cancer patients (99.6\%) at the $\mathrm{BPKMCH}$ were found to be using face masks in contrast to a web-based survey conducted in the Bangladeshi population, which showed $75.5 \%$ population using face mask regularly. ${ }^{20}$ The practice of using the same face mask among the participants of this study was for more than 3 days which was similar to the study done in Bangladesh. Interestingly, in our study almost all the participants used a face mask, and nearly $90 \%$ had a positive attitude to accept hospital-based isolation if diagnosed with COVID-19. This finding is relatively higher than that of another study done among the Egyptian population in which only 35\% were willing to use a face mask, and nearly $60 \%$ of the participants were willing to accept hospital-based isolation if diagnosed with COVID-19. ${ }^{21}$ The high positive practice and attitude levels in this study could be attributed to the hospital-based settings of the study where strict prevention and control measures are implemented by the hospital management, and there are availability and easy access to the health professionals' advice or consultation, and information, education, communication or behavior change communication materials in the hospital. Also, it could be because the patients already had a good knowledge on COVID-19 gained from audio-visual and various other sources. Unfortunately, the present study still showed that $4.5 \%$ of patients recently went to crowded places and $1.8 \%$ did not wear masks at all.

Despite good knowledge, attitude, and practice for prevention of COVID-19, the patients in this research had limited information regarding the proper use of face mask and covering, since a large proportion were using the same face mask for several days without washing in between. In this regard, the study observed the necessity of creating awareness on the proper use of face mask, washing cloth face mask after each use, and avoiding the reuse of non-reusable disposable face masks. This study also observed that more than half of the patients had more than one caretaker. This reflects the violation of the hospital rule of allowing only one caretaker per patient in the hospital premises which can negatively affect the preventive measures taken by the hospital. This is further supported by the fact that $66 \%$ of the caretakers are staying in the hospital itself. However, this can be due to the unavailability of hotels, as the country is still in lockdown.
There are some limitations to this study. With a reduced number of patients in the BPKMCH in the context of the ongoing lockdown and due to difficulty in transportation, the current study was conducted among a comparatively smaller sample size. Also, this study was conducted in only one hospital, and among the admitted cancer patients; hence, it cannot be generalized to a wider population. However, $\mathrm{BPKMCH}$ is the biggest cancer center in Nepal with many patients seeking cancer treatment. As this is a cross-sectional study design and has used the convenient sampling method, it is not able to determine the casualty, which is another limitation of this study. Unlike a few other studies conducted via a web-based survey, our study was conducted through a face-to-face interview method. This helped us avoid the bias of excluding the underprivileged population without access to the internet. Besides, it ensured better comprehension and interpretation of responses to the questionnaires and allowed providing additional information about preventive behaviors in patients.

\section{Conclusions}

The study reveals that the overwhelming majority of the cancer patients in central Nepal have general information regarding COVID-19 and maintain a positive attitude and practice for protecting themselves against it. Thus, it indicates the efficacy of the present public health and hospital campaigns regarding COVID-19. However, the results also reveal that age, gender and education should be taken into consideration when the policy-makers plan for the further tailored health education programs. Health education should also focus on proper use and reuse of the different types of facemasks.

\section{Acknowledgment}

The authors would like to thank the participants and their caretakers for their co-operation and making this study possible. We would also like to thank Pushpa Acharya and Pragya Paneru for editing the manuscript.

\section{Disclosure}

The authors report no conflicts of interest for this work.

\section{References}

1. Zhu N, Zhang D, Wang W, et al. A novel coronavirus from patients with pneumonia in China, 2019. $N$ Engl $J$ Med. 2020;382:727-733. doi:10.1056/NEJMoa2001017

2. World Health Organization (WHO). Coronavirus disease 2019 (COVID-19): situation report, 145; Published 2020. Available from: https://www.who.int/docs/default-source/coronaviruse/situation-reports /20200613-covid-19-sitrep-145.pdf?sfvrsn=bb7c1dc9_2. Accessed June 14, 2020. 
3. Ministry of Health and Population (MoHP). MoHP Nepal COVID-19 update. MoHP; Published 2020. Available from: https://covid19. mohp.gov.np/\#/. Accessed June 14, 2020.

4. Centers for Disease Control and Prevention. Coronavirus Disease 2019 (COVID-19). Symptoms of Coronavirus; Published 2020. Available from: https://www.cdc.gov/coronavirus/2019-ncov/symp toms-testing/symptoms.html. Accessed June 4, 2020.

5. Mizumoto K, Kagaya K, Zarebski A, Chowell G. Estimating the asymptomatic proportion of coronavirus disease 2019 (COVID-19) cases on board the Diamond Princess cruise ship, Yokohama, Japan, 2020. Eurosurveillance. 2020;25(10):2000180. doi:10.2807/15607917.ES.2020.25.10.2000180

6. World Health Organization (WHO). Coronavirus disease 2019: coronavirus disease (COVID-19) advice for the public. World Health Organisation; Published 2020. Available from: https://www.who.int/ emergencies/diseases/novel-coronavirus-2019/advice-for-public. Accessed June 4, 2020.

7. Centers for disease control and prevention. Recommendation regarding the use of cloth face coverings, especially in areas of significant community-based transmission. CDC; Published 2020. Available from: https://www.cdc.gov/coronavirus/2019-ncov/prevent-gettingsick/cloth-face-cover.html. Accessed June 4, 2020.

8. Zheng Z, Peng F, Xu B, et al. Risk factors of critical \& mortal COVID-19 cases: A systematic literature review and meta-analysis. $J$ Infect. 2020;81:e16e25. doi:10.1016/j.jinf.2020.04.021

9. Liang W, Liang $\mathrm{H}$, Ou L, et al. Development and validation of a clinical risk score to predict the occurrence of critical illness in hospitalized patients with COVID-19. JAMA Intern Med. 2020: e202033. doi:10.1001/jamainternmed.2020.2033.

10. Onder G, Rezza G, Brusaferro S. Case-fatality rate and characteristics of patients dying in relation to COVID-19 in Italy. JAMA. 2020;323 (18):1775-1776. doi:10.1001/jama.2020.4683

11. Kuderer NM, Choueiri TK, Shah DP, et al. Clinical impact of COVID-19 on patients with cancer (CCC19): a cohort study. Lancet. 2020;395:1907-1918. doi:10.1016/S0140-6736(20)31187-9

12. World Health Organization (WHO). Report of the WHO-China Joint Mission on Coronavirus Disease 2019 (COVID-19). WHO; Published 2020. Available from: https://www.who.int/docs/defaultsource/coronaviruse/who-china-joint-mission-on-covid-19-finalreport.pdf. Accessed June 4, 2020.
13. GLOBOCAN. The global cancer observatory: Nepal factsheet. International Agency for Research on Cancer, World Health Organization; Published 2018. Available from: http:/gco.iarc.fr/ today/data/factsheets/populations/524-nepal-fact-sheets.pdf.

Accessed July 1, 2019.

14. B.P. Koirala Memorial Cancer Hospital. Annual Report. 2018.

15. Zhong B-L, Luo W, Li H-M, et al. Knowledge, attitudes, and practices towards COVID-19 among Chinese residents during the rapid rise period of the COVID-19 outbreak: a quick online cross-sectional survey. Int J Biol Sci. 2020;16(10):1745. doi:10.7150/ijbs.45221

16. Ministry of Health and Population (MoHP). MOHP Nepal COVID-19 situation report 44. MoHP, Nepal; Published 2020. Available from: https://rive.google.com/drive/folders/ 1INZsSsX5t0P9oWtwdQh0iL0_r7psAWOx.

17. Vaidya B, Bhochhibhoya M, Baral R, Nakarmi S. Knowledge, attitude and practice regarding COVID-19 among patients with musculoskeletal and rheumatic diseases in Nepal: a web- based cross-sectional study. Open Access Rheumatol. 2020;Volume 12:167-173. doi:10.2147/OARRR.S265816

18. Azlan AA, Hamzah MR, Sern TJ, Ayub SH, Mohamad E. Public knowledge, attitudes and practices towards COVID-19: A cross-sectional study in Malaysia. PLoS One. 2020;15(5):e0233668. doi:10.1371/journal.pone. 0233668

19. Singh DR, Sunuwar DR, Karki K, Ghimire S, Shrestha N. Knowledge and perception towards universal safety precautions during early phase of the COVID-19 outbreak in Nepal. $J$ Community Health. 2020. doi:10.1007/s10900-020-00839-3

20. Haque T, Hossain KM, Bhuiyan MMR, et al. Knowledge, attitude and practices (KAP) towards COVID-19 and assessment of risks of infection by SARS-CoV-2 among the Bangladeshi population: an online cross sectional survey. Res Sq. 2020. doi:10.21203/rs.3.rs$24562 / \mathrm{v} 1$

21. Abdelhafiz AS, Mohammed Z, Ibrahim ME, et al. Knowledge, perceptions, and attitude of Egyptians towards the novel coronavirus disease (COVID-19). J Community Health. 2020:1-10. doi:10.1007/ s10900-020-00827-7.

\section{Publish your work in this journal}

Cancer Management and Research is an international, peer-reviewed open access journal focusing on cancer research and the optimal use of preventative and integrated treatment interventions to achieve improved outcomes, enhanced survival and quality of life for the cancer patient.
The manuscript management system is completely online and includes a very quick and fair peer-review system, which is all easy to use. Visit http://www.dovepress.com/testimonials.php to read real quotes from published authors. 